\title{
KUALITAS AKADEMIK YANG MEMPENGARUHI KEPUTUSAN CALON MAHASISWA DALAM MEMILIH PROGRAM STUDI PENDIDIKAN EKONOMI PADA FAKULTAS KEGURUAN DAN ILMU PENDIDIKAN UNIVERSITAS ISLAM SYEKH-YUSUF TANGERANG TAHUN 2018
}

\author{
Oleh: Estu Niana Syamiya1, Yusuf Budiana Tanu², Hawalina Rizkiana Dewi ${ }^{3}$ \\ (UNIVERSITAS ISLAM SYEKH-YUSUF TANGERANG) \\ 1) ensyamiya@unis.ac.id
}

\begin{abstract}
Abstrak-Penelitian ini dilaksanakan di Fakultas Keguruan dan Ilmu Pendidikan Program Studi Pendidikan Ekonomi Universitas Islam Syekh-Yusuf Tangerang. Penelitian ini bertujuan untuk mengetahui sejauh mana pengaruh Kualitas Akademik terhadap Keputusan Calon Mahasiswa dalam memilih Program Studi Pendidikan Ekonomi pada Fakultas Keguruan dan Ilmu Pendidikan Universitas Islam Syekh-Yusuf Tangerang. Penelitian ini menggunakan metode kuantitatif dengan model penelitian yaitu deskriptif korelasi dan teknik pengumpulan data berupa kuesioner. Jumlah populasi dalam penelitian ini adalah 194 mahasiswa yang kemudian ditetapkan dengan menggunakan teknik sampling yaitu simple random sampling sehingga didapat sampel yaitu sebanyak 131 mahasiswa. Berdasarkan hasil perhitungan secara parsial Kualitas Akademik terhadap Keputusan Calon Mahasiswa diperoleh nilai koefisien regresi 0,629. Pada taraf signifikansi 5\%, dapat diketahui thitung sebesar 9,097 dengan nilai signifikansi sebesar 0,000 karena koefisien regresi mempunyai nilai positif dan nilai signifikansi <0,05. Hal ini dapat disimpulkan bahwa Kualitas Akademik terdapat pengaruh positif dan signifikan terhadap Keputusan Calon Mahasiswa dalam memilih Program Studi Pendidikan Ekonomi.
\end{abstract}

Kata Kunci: Kualitas Akademik, Keputusan Calon Mahasiswa

\begin{abstract}
This research was carried out in the Faculty of Teacher Training and Education in the Economic Education Study Program of the Islamic University of Syekh-Yusuf Tangerang. This study aims to determine the extent of the influence of Academic Quality on Student Candidate Decisions in choosing the Economic Education Study Program at the Teaching and Education Faculty of the Islamic University of Syekh-Yusuf Tangerang. This study uses a quantitative method with a research model that is descriptive correlation and data collection techniques in the form of questionnaires. The population in this study is 194 students which is then determined by using a sampling technique that is simple random sampling so that a sample of 131 students is obtained. Based on the partial calculation of Academic Quality on Student Candidate Decisions, the regression coefficient value is 0.629. At a significance level of 5\%, it can be seen that tcount is 9.097 with a significance value of 0.000 because the regression coefficient has a positive value and a significance value of $<0.05$. It can be concluded that
\end{abstract}


Academic Quality has a positive and significant influence on the Prospective Student's Decision in choosing the Economic Education StudyProgram.

Keywords: Academic Quality, Decision of Prospective Students

\section{PENDAHULUAN}

Kompetensi

kualitas

akademik perguruan tinggi selalu menjadi perhatian dan mendapat kritikan dari berbagai pihak karena dianggap memiliki kualitas yang buruk. Diantaranya, pelayanan akademik tenaga kependidikan yang tidak baik dan fasilitas perkuliahan yang tidak mendukung perkuliahan bahkan kompetensi dosen yang tidak sesuai dalam memberikan mata kuliah. Keadaan ini semakin didukung dari pihak Yayasan dan Universitas dan terkadang berbeda terhadap fakultas-fakultas tertentu dalam lingkup universitasitu sendiri. Pihak pengelola lembaga pendidikan tinggi sering mengabaikan dan tidak melihat apa yang diinginkan oleh mahasiswa. Dengan kata lain, jika ingin kualitas akademik baik dipandang mahasiswa dan masyarakat secara umum maka pengelola lembaga pendidikan harus memperhatikan kualitas yang diberikan.

Mahasiswa sebagai individu yang ingin meningkatkan kecerdasan akademikakan berupaya mencari sumber pendidikan yang dapat memberikan input yang baik sesuai dengan potensi yang dimiliki. Oleh karena kebutuhan dunia usaha saat ini lebih memilih individu-individu yang mempunyai kecerdasan dan skill, pendidikan memegang pengaruh yang besar untuk menghasilkan individu-individu yang siap kerja di dunia usaha atau dalam masyarakat. Pendidikan sangatlah penting dalam kehidupan manusia dan tidak terbatas pada umur. Suatu negara yang mutu pendidikannya rendah akan mengakibatkan terhambatnya pembangunan.

Menurut UU No 12 Tahun 2012 tentang Pendidikan Tinggi pada pasal 1 ayat 1 , bahwa Pendidikan Tinggi adalah jenjang pendidikan setelah pendidikan menengah yang mencakup program diploma, program sarjana, program magister, program doktor, dan program profesi, serta program spesialis, yang diselenggarakan oleh perguruan tinggi berdasarkan kebudayaan bangsa Indonesia.

Kenyataan yang terjadi di masyarakat umum dan calon mahasiswa baru khususnya, masih mempertimbangkan tentang kualitas akademik perguruan tinggi dengan melihat status akreditasi, dosen, suasana akademik di lingkungan kampus, pelayanan akademik, keamanan dan kenyamanan saat berada di kampus. Hal ini adalah yang menjadi indikator pilihan di kalangan calon mahasiswa baru, termasuk masyarakat umum, juga pada institusi pengguna lulusan. 
Terlebih lagi bila yang dipilih adalah perguruan tinggi swasta. Selain akreditasi program studi, peluang kerja guru ekonomi juga merupakan dasar keinginan mahasiswa dalam memilih program studi pendidikan ekonomi.

Pada beberapa tahun ini, profesi guru di Indonesia mulai banyak diminati oleh masyarakat. Guru adalah sebuah profesi yang sangat baik dan sangat dibutuhkan di Indonesia. Banyak calon mahasiswa yang melanjutkan ke perguruan tinggi memilih masuk Fakultas Keguruan dan Ilmu Pendidikan dengan tujuan untuk berprofesi menjadi guru.

Program Studi Pendidikan Ekonomi FKIP UNIS selalu mengikuti perkembangan kebutuhan guru di Indonesia secara umum dan di Propinsi Banten khususnya. Prodi Pendidikan Ekonomijuga membekali lulusan dengan dua dasar keilmuan yaitu keilmuan pendidikan dan keilmuan ekonomi. Sehingga lulusan Prodi Pendidikan Ekonomimampu berkompetisi dalam dua peluang kerja, yaitu peluang kerja keguruan dan kependidikan juga dapat mengisi peluang kerja dalam bidang bisnis dan industri.Dengan demikian lulusan mahasiswa FKIP Prodi Pendidikan Ekonomi seharusnya mampu menghasilkan lulusan yang dapat berkompetisi dalam masyarakat, yang dibutuhkan pada masa sekarang ini. Sumber daya manusia yang kompeten di bidang keguruan.

\section{TINJAUAN TEORITIS \\ Pengertian Keputusan}

Pengambilankeputusandapatme nentukansuatuhasildari proses mental ataukognitif yang membawapadapemilihansuatujalurtin dakan di antarabeberapa alternatif yang tersedia. Setiap proses pengambilankeputusanselalumengha silkansatupilihan final.

Irham Fahmi dalam bukunya Teori dan Teknik Pengambilan Keputusan (2016: 2) mendefinisikan bahwa keputusan adalah proses penelusuran masalah yang berawal dari latar belakang masalah, identifikasi masalah hingga kepada terbentuknya kesimpulan atau rekomendasi. Rekomendasi itulah yang selanjutnya dipakai dan digunakan sebagai pedoman dasar dalam pengambilan keputusan. Oleh karena itu, begitu besarnya pengaruh yang akan terjadi jika seandainya rekomendasi yang dihasilkan terdapat kekeliruan atau kesalahankesalahan yang tersembunyi karena faktor ketidak hati-hatian dalam pengkajian masalah.

\section{Dasar Pengambilan Keputusan}

George R. Terrydalam Syamsi, (2000:16) menyebutkan 5 dasar (basis) dalam pengambilan keputusan, yaitu : intuisi, pengalaman, fakta, wewenang, dan rasional. 
1) Intuisi.

\begin{tabular}{lcr} 
Pengambilan & \multicolumn{2}{r}{ keputusan } \\
berdasarkan & intuisi & adalah \\
pengambilan & keputusan & yang \\
berdasarkan & perasaan & yang \\
sifatnya & subyektif & Dalam
\end{tabular}
sifatnya subyektif. Dalam pengambilan keputusan berdasarkan intusi ini, meski waktu yang digunakan untuk mengambil keputusan relatif pendek, tetapi keputusan yang dihasilkan seringkali relatif kurang baik karena seringkali mengabaikan dasardasar pertimbangan lainnya.

2) Pengalaman.

Pengambilan keputusan berdasarkan pengalaman memiliki manfaat bagi pengetahuan praktis, karena dengan pengalaman yang dimiliki seseorang, maka dapat memperkirakan keadaan sesuatu, dapat memperhitungkan untungruginya dan baik-buruknya keputusan yang akan dihasilkan.

3) Wewenang.

Pengambilan keputusan berdasarkan wewenang biasanya dilakukan oleh pimpinan terhadap bawahannya, atau oleh orang yang lebih tinggi kedudukannya kepada orang yang lebih rendah kedudukannya. Hasil keputusannya dapat bertahan dalam jangka waktu yang cukup lamadan memiliki otentisitas (otentik), yang akan tetapi dapat menimbulkan sifat rutinitas, mengasosiasikan dengan praktek diktatorialdan sering melewati permasalahan yang seharusnya dipecahkan sehingga dapat menimbulkan kekaburan.

4) Fakta.

Pengambilan keputusan berdasarkan data dan fakta empiris dapat memberikan keputusan yang sehat, solid dan baik. Dengan fakta, tingkat kepercayaan terhadap pengambil keputusan dapat lebih tinggi, sehingga orang dapat menerima keputusan yang dibuat itu dengan rela dan lapang dada.

5) Rasional.

Pada pengambilan keputusan yang berdasarkan rasio, keputusan yang dihasilkan bersifat objektif, logis, lebih transparan dan konsisten untuk memaksimumkan hasil atau nilai dalam batas kendala tertentu, sehingga dapat dikatakan mendekati kebenaran atau sesuai dengan apa yang diinginkan. Pengambilan keputusan secara rasional ini berlaku sepenuhnya dalam keadaan yang ideal. Pada pengambilan keputusan secara rasional terdapat beberapa hal sebagai berikut:

a) Kejelasan masalah: tidak ada keraguan dan kekaburan masalah.

b) Orientasi tujuan: kesatuan pengertian tujuan yang ingin dicapai.

c) Pengetahuan alternatif: seluruh alternatif diketahui jenisnya dan konsekuensinya. 
d) Preferensi yang jelas: alternatif bisa diurutkan sesuai kriteria.

e) Hasil maksimal: pemilihan alternatif terbaik berdasarkan atas hasil ekonomis yang maksimal.

\section{Keputusan Calon Mahasiswa}

Calon mahasiswa saat ini cenderung memilih program studi sesuai dengan bakat dan kompetensi, baik perguruan tinggi negeri mau pun swasta dengan melihat beberapa kriteria yang diunggulkan sebuah fakultas.Mengetahui dosen-dosen dalam memberi kuliah, mendapatkan informasi tentang status akreditasi perguruan tinggi dan akreditasi program studinya. Informasi ini sangat diperlukan karena beberapa institusi yang menerima para lulusan perguruan tinggi saat ini telah menjadi sebagai indikator kualitas sumber daya manusia yaitu dengan melihat kondisi yang akurat dari perguruan tinggi tersebut.

\section{Pengertian Kualitas}

Menurut ISO-8402 (Loh, 2001:35), bahwa Kualitas adalah totalitas fasilitas dan karakteristik dari produk atau jasa yang memenuhi kebutuhan, tersurat maupun tersirat.

Jadi dapat disimpulkan bahwa kualitas merupakan suatu kondisi dinamis yang berhubungan dengan produk, jasa, manusia, proses dan linkungan yang memenuhi atau melebihi harapan.

\section{Kualitas Akademik}

Menurut Juran, Cosby dalam Rahman, (2006:60) menggunakan empat belas langkah untuk meningkatkan kualitas atau mutu:

1) Komitmen mutu dalam manajemen harus jelas.

2) Adanya penyusunan tim kualitas dengan wakilnya dalam organisasi (gugus kendali mutu).

3) Menerapkan sosialisasi dan asesmen mutu yang menjadi pegangan setiap pekerja.

4) Adanya peningkatan terhadap pemahaman kualitas diantara setiap pekerja.

5) Membuat tindakan korektif apabila ada masalah dalam manajemen.

6) Membentuk tim atau panitia untuk menghilangkan kesalahan.

7) Memberi pelatihan kepada karyawan.

8) Menciptakan hari tanpa kesalahan.

9) Meningkatkan kepedulian para karyawan untuk menciptakan sasaran mutu dan pedoman mutu bagi kebutuhan pribadi mereka.

10) Memberikan bimbingan kepada para pekerja untuk selalu berkomunikasidenganpimpinan mengenai hambatan-hambatan dalam mencapai sasaranmutu.

11) Pimpinan wajib mengenali siapapun yang berpartisipasi dalam meraih sasaran mutu. 
12) Menyusun tim kualitas untuk melakukan peningkatan mutu secara terus-menerus.

Berdasarkan beberapa definisi di atas, dapat dikemukakan bahwa kualitas ataumutu mempunyai unsurunsur:

1) Pelayanan akademik dan pengurus fakultas harus memiliki dedikasi yang baik.

2) Lulusan yang outcome (siap pakai).

3) Lingkungan yang kondusif akan menentukan banyak sedikitnya jumlah peminat.

4) Kondisi mahasiswa baru yang selektif wajib diperhatikan dengan baik.

5) Dosenyang mengajarharusmemilikikompetens idengansertifikasi.

\section{Penelitian yang Relevan}

1. Erlita Risnawati, dan Soni Agus Irwan ditelah menjelaskan bahwa didalam jurnalnya menggunakan model penelitian accidental sampling dengan teknik penelitian yang sama yaitu accidental sampling dan hasil penelitian ini bertujuan untuk meneliti faktor yang dapat mempengaruhi mahasiswa untuk memilih jurusan akuntansi di STIE Perbanas Surabaya dengan sampel 435 mahasiswa akuntansi angkatan 2011.

2. Dewa Ayu Juli Artini, Ketut Kirya, dan Wayan Suwendra telah menjelaskan bahwa didalam jurnalnya menggunakan model penelitian desain eksplorasi sedangkan teknik penelitian yang digunakan yaitu non probability sampling dan hasil penelitian ini menunjukkan bahwa terdapat dua faktor yang mempengaruhi keputusan mahasiswa dalam memilih jurusan di Fakultas Ekonomi dan bisnis Undiksha sebagai tempat kuliah, yaitu 1 . Faktor lingkungan internal yang mencakup produk, harga, promosi, orang, dan proses, 2 . Faktor lingkungan eksternal yaitu kelompok acuan, kemauan sendiri, dan keluarga.

3. Dedy Ansari Harahap, Ratih Hurriyati, Vanessa Gaffar, Lili Adi Wibowo, dan Dita Amanah telah menjelaskan bahwa didalam jurnalnya menggunakan model penelitian regresi linier sederhana sedangkan teknik penelitian yang digunakan yaitu non probability sampling dan hasil penelitian ini Menunjukkan variabel reputasi universitas positif berpengaruh signifikan terhadap keputusan mahasiswa memilih studi.

4. Nur Kholis, dan Meri Kartika telah menjelaskan bahwa di dalam jurnalnya menggunakan model penelitian Multiple linear regression sedangkan teknik penelitian yang digunakan yaitu Accidental sampling: prospective students of Islamic Economics Program FIAI UII year 2011- 
2014 dan hasil penelitian ini The result of this research showed that variable variable of education cost 25.41390, variable of education facility 24.48315, campus image variable and big name UII 14.28829, job opportunity variable 22.21724 , parent motivation variable and information from brochure 26.81530, significantly influenced student interest choosing economics department Islam FIAI UII. While simultaneously, it is concluded that $98 \%$ of students choose lectures in Islamic Economics Program influenced by the variables above and $2 \%$ other influenced by the variable not examined in this study.

5. Mahbubar Rahman, dan Rafkul Islam telah menjelaskan bahwa didalam jurnalnya menggunakan model penelitian Usinga qualitative sedangkan teknik penelitian yang digunakan yaitu Employing interviews dan hasil penelitianini The study reveals that as a HLI of Malaysia, IIUM has a good reputation among the international students although the level of positivityvaries from case to case. The results are primarily benefcial to academics and researchers to understand the related issues of how the foreign students select their institution for pursuing higher studies.

\section{Kerangka Pemikiran}

Berdasarkan landasan teoritis yang sudah dipaparkan maka tersusun kerangka pemikiran penelitian,kerangka konseptual berikut juga menjadi dasarbagi penulis untuk menentukan hipotesis penelitian. Dalam penelitian ini dapat dilihat kerangka berpikir sebagai berikut:
Variabel X

KUALITAS AKADEMIK

a. Pelayanan Akademik, dan Pengurus Fakultas

b. Lulusan yang outcome (siap pakai)

c. Lingkungan yang kondusif

d. Kondisi mahasiswa baru yang selektif

\section{Variabel Y}

\begin{tabular}{|l|}
\hline KEPUTUSAN CALON \\
MAHASISWA \\
a. Wewenang \\
b. Intuisi \\
c. Pengalaman \\
d. Fakta \\
e. Rasional \\
\hline
\end{tabular}

Gambar 1. Kerangka Berpikir 


\section{Hipotesis Penelitian}

Hipotesis dalam penelitian ini adalah:

$\begin{array}{rlr}\text { Ho }=0 & \text { Kualitas Akademik tidak } \\ & \text { berpengaruh } & \text { terhadap } \\ & \text { Keputusan } & \text { Calon } \\ & \text { Mahasiswa dalam memilih } \\ & \text { Program Studi } & \text { Pendidikan } \\ & \text { Ekonomi. } \\ \mathrm{Ha}=0 & \begin{array}{l}\text { Kualitas } \\ \text { berpengaruh }\end{array} \\ & \text { Keputusan } \\ & \text { Mahasiswa dalam memilih } \\ & \text { Program Studi Pendidikan } \\ & \text { Ekonomi. }\end{array}$

\section{METODE PENELITIAN}

Penelitian ini menggunakan metode deskriptif yang bertujuan untuk menjelaskan serta meringkaskan berbagai kondisi, situasi, deskriptif untuk melihat hubungan atau berbagai variabel yang timbul di masyarakat yang menjadi objek penelitian itu berdasarkan apa yang terjadi. Peneliti menggunakan metode antara variabel bebas (kualitas akademik) dengan variable terikat (keputusan mahasiswa). Penelitian deskriptif ini menggambarkan apa yang sesungguhnya terjadi di tempat penelitian dan menggunakan data yang diperoleh dari objek yang akan diteliti pada tempat tersebut dalam hal ini pada Universitas Islam Syekh Yusuf Tangerang.

Data yang digunakan dalam penelitian ini adalah data primer dan data skunder. Data primer adalah data yang diperoleh dari tangan pertama yang dikumpulkan secara langsung dari sumbernya, dan untuk mendapatkan data primer ini peneliti harus mengumpulkannya secara langsung melalui teknik observasi dan penyebaran kuisoner. Sedangkan data sekunder adalah data informasi dari tangan kedua yang sudah dikumpulkan oleh beberapa orang (organisasi) untuk tujuan tertentu dan tersedia untuk berbagai penelitian.

Tabel 1. Jumlah Populasi Penelitian

\begin{tabular}{|c|c|c|}
\hline No & Mahasiswa FKIP Ekonomi & Jumlah Populasi \\
\hline 1 & Semester 2 & 43 Mahasiswa \\
\hline 2 & Semester 4 & 40 Mahasiswa \\
\hline 3 & Semester 6 & 38 Mahasiswa \\
\hline 4 & Semester 8 & 73 Mahasiswa \\
\hline & Jumlah & 194 Mahasiswa \\
\hline
\end{tabular}

Sumber: Data Tata Usaha FKIP UNIS Tahun 2018 
Tabe 2. Jumlah Sampel Penelitian

\begin{tabular}{|c|c|c|}
\hline No & Mahasiswa FKIP Ekonomi & Jumlah Sampel \\
\hline 1 & Semester 2 & $43 / 194 \times 131=29$ \\
\hline 2 & Semester 4 & $40 / 194 \times 131=27$ \\
\hline 3 & Semester 6 & $38 / 194 \times 131=26$ \\
\hline 4 & Semester 8 & $73 / 194 \times 131=49$ \\
\hline & Jumlah & 131 \\
\hline
\end{tabular}

Sumber: Data UPT Marketing UNIS Tahun 2018

Teknik pengumpulan data yang digunakan dalam penelitian ini adalah kuesioner/angket. Skala pengukuran yang digunakan dalam angket di penelitian ini adalah skalalikert. Instrument yang telah disusun kemudian dilakukan ujicoba kepada 31 orang responden.

Variabel independen: variable ini sering disebuts ebagai variabel stimulus, predictor, antecedent. Variabel independen yang digunakan dalam penelitian ini yaitu Kualitas Akademik (X) Variabeld ependen: sering disebut sebagai variabel output, kriteria, konsekuen. Variabel dependen yang digunakan dalam penelitianini yakni Keputusan Mahasiswa (Y).

Metode yang digunakan dalam penelitian ini adalah metode kuantitatif. Data dianalisis dengan analisis statistic deskriptif, analisis regresi sederhana, analisis normalitas, analisis linearitas, analisis koefisien determinasi dan uji hipotesis dengan uji $\mathrm{T}$ dengan bantuan program SPSS Statistic 22.

3. HASIL DAN PEMBAHASAN

Tabel 3. HasilUji T

Coefficients $^{\text {a }}$

\begin{tabular}{|c|c|c|c|c|c|c|}
\hline & \multirow[b]{2}{*}{ Model } & \multicolumn{2}{|c|}{$\begin{array}{l}\text { Unstandardized } \\
\text { Coefficients }\end{array}$} & $\begin{array}{l}\text { Standardized } \\
\text { Coefficients }\end{array}$ & \multirow[b]{2}{*}{$\mathrm{T}$} & \multirow[b]{2}{*}{ Sig. } \\
\hline & & B & Std. Error & Beta & & \\
\hline \multirow[t]{2}{*}{1} & (Constant) & 17.816 & 2.821 & & 6.315 & .000 \\
\hline & $\begin{array}{l}\text { Kualitas } \\
\text { Akademik (X) }\end{array}$ & .629 & .069 & .625 & 9.097 & .000 \\
\hline
\end{tabular}

a. Dependent Variable: Keputusan Calon Mahasiswa (Y)

Berdasarkan hasil perhitungan di atas secara parsial Kualitas Akademik berpengaruh terhadap
Keputusan Calon Mahasiswa, diperoleh nilai koefisien regresi 0,629. Pada taraf signifikansi 5\%, 
dapat diketahui $\mathrm{t}$ hitung sebesar 9,097 dengan nilai signifikansi sebesar 0,000 karena koefisien regresi mempunyai nilai positif dan nilai signifikans $<0,05$ maka dapat disimpulkan bahwa Kualitas Akademik terdapat pengaruh positif dan signifikan terhadap Keputusan Calon Mahasiswa dalam memilih Program Studi Pendidikan Ekonomi pada FKIP UNIS Tangerang.

Hasil penelitian ini selaras dengan penelitian sebelumnya yang di lakukan oleh Dedy Ansari Harahap, Ratih Hurriyati, Vanessa Gaffar, Lili Adi Wibowo, Dita Amanah, (2017) mengenai "Pengaruh Reputasi Universitas Terhadap Keputusan Mahasiswa Memilih Studi Di Universitas Islam Sumatera Utara". Hasil penelitian yang telah dilakukan pada variable Reputasi Universitas positif berpengaruh secara signifikan terhadap Keputusan Mahasiswa memilih Studi di Fakultas Ekonomi UISU Indonesia. Dapat dilihat dari nilai koefisien regresi Reputasi Universitas dengan uji parsial (uji T) dengan nilai $\mathrm{t}$ hitung $>\mathrm{t}$ table yaitu $15,608>1,654$ pada tingkat signifikansi $0,000<0,05$ yang berarti signifikan untuk menilai Keputusan Mahasiswa memilih Studi karena lebih kecil dari 5\%, maka hipotesis diterima, artinya positif terdapat pengaruh secara signifikan antara Reputasi Universitas terhadap Keputusan Mahasiswa memilih Studi di Fakultas Ekonomi UISU Indonesia.

Reputasi adalah kombinasi antara opini, persepsi dan perilaku setiap individu atau organisasi dalam memberikan penilaian sepanjang waktu tentang performa organisasi atau perusahaan berdasarkan pada keterkaitan emosi, finansial, social dan kultural antara organisasi dengan yang berkepentingan. Reputasi Universitas menjadi hal yang sangat penting untuk dipertimbangkan oleh calon mahasiswa dalam menentukan sikap tepat untuk melanjutkan studi di Perguruan Tinggi sesuai kebutuhan dan keinginan. Reputasi Universitas dapat diukur dari kepopuleran nama Universitas, jumlah pendaftar secara keseluruhan dan rasio antara jumlah yang diterima dengan jumlah pendaftar.

\section{KESIMPULAN DAN SARAN Kesimpulan}

Terdapat hubungan dan pengaruh yang positif antara Kualitas Akademik dengan Keputusan Calon Mahasiswa FKIP UNIS tahun 2018. Hal itu dapat dilihat dari perhitungan dengan menggunakan korelasi product moment. Berdasarkan hasil perhitungan secara parsial Kualitas Akademik berpengaruh terhadap Keputusan Calon Mahasiswa, diperoleh nilai koefisien regresi 0,629 . Pada taraf signifikansi 5\%, dapat diketahui thitung sebesar 9,097 dengan nilai signifikansi sebesar 0,000 karena koefisien regresi 
mempunyai nilai positif dan nilai signifikansi< 0,05 maka dapat disimpulkan bahwa Kualitas Akademik terdapat pengaruh positif dan signifikan terhadap Keputusan Calon Mahasiswa dalam memilih Program Studi Pendidikan Ekonomi pada FKIP UNIS Tangerang.

\section{Saran}

Berdasarkan simpulan tersebut, maka disarankan beberapa hal tersebut:

1. Mahasiswa sebaiknya dalam memilih program studi yang ada di suatu perguruan tinggi harus lebih mempertimbangkan pemahaman, kemampuan dan keyakinan diri terhadap pengambilan keputusan yang nantinya akan dipilih. Sehingga keputusan yang diambil sesuai dengan harapan dan output yang dihasilkan lebih maksimal.

2. Keluarga, sekolah, dan perguruan tinggi diharapkan ikut serta dalam memberikan pengarahan yang positif terhadap keputusan calon mahasiswa dalam memilih program studi. Dengan adanya dukungan dan dorongan dari beberapa pihak maka calon mahasiswa akan lebih mantap, percaya diri dan yakindalam pengambilan keputusan bagi masa depannya.

\section{REFERENSI}

Buchori, Alma. 2013. Manajemen Pemasaran dan Pemasaran Jasa. Bandung: Alfabeta.

Hasan. 2004. Pokok-Pokok Materi Pengambilan Keputusan. Bogor: Ghalia Indonesia.

Irham, Fahmi. 2016. Teori Dan Teknik Pengambilan Keputusan. Jakarta.

Sugiyono. 2012. Metode Penelitian Pendidikan Bandung: Alfabeta.

Sugiyono. 2013. Statistika Untuk Penelitian. Bandung: Alfabeta.

Syamsi. Ibnu. 2000. Pengambilan Keputusan dan Sistem Informasi. Jakarta: Bumi Aksara.

Ayu. 2014. "Faktor-Faktor Yang Mempengaruhi Keputusan Mahasiswa dalam Memilih Jurusan di Fakultas Ekonomi Dan Bisnis (Feb) Universitas Pendidikan Ganesha (Undiksha) Sebagai Tempat Kuliah". Journal Bisma Universitas Pendidikan Ganesha Jurusan Manajemen, 2 (1).

Harahap. 2017. "Pengaruh Reputasi Universitas Terhadap Keputusan Mahasiswa Memilih Studi di Universitas Islam Sumatera Utara". PROSIDING SEMINAR NASIONAL \& KONFERENSI Forum Manajemen Indonesia (FMI 9), Semarang, (9), 1-12. https://doi.org/10.17605/OSF.I O/8ZG6N

Rahman. 2017. Selection of Institution of Higher Learning for Study Abroad: A Malaysian Case Study, 51 (1), $33-48$ 
Risnawati. 2012. "Analisis Faktor Atas Pengambilan Keputusan Mahasiswa". The Indonesian Accounting Review, 2 (Sistem Pengambilan Keputusan), 6372.

https://doi.org/10.14414/tiar.v2 i01.318 